\title{
Financial toxicity and implications for cancer care in the era of molecular and immune therapies
}

\author{
George $\operatorname{Tran}^{1}$, S. Yousuf Zafar ${ }^{1,2}$ \\ ${ }^{1}$ Duke University School of Medicine, Durham, NC, USA; ${ }^{2}$ Duke Cancer Institute, Duke-Margolis Center for Health Policy, Durham, NC, USA \\ Contributions: (I) Conception and design: All authors; (II) Administrative support: None; (III) Provision of study materials or patients: None; (IV) \\ Collection and assembly of data: All authors; (V) Data analysis and interpretation: All authors; (VI) Manuscript writing: All authors; (VII) Final \\ approval of manuscript: All authors. \\ Correspondence to: S. Yousuf Zafar, MD, MHS. 2424 Erwin Road, Suite 602, Room 6046, Durham, NC 27705, USA. Email: yousuf.zafar@duke.edu.
}

\begin{abstract}
Molecular and immune therapies have revolutionized cancer treatment and improved patient outcomes and survival. However, the pricing of these drugs has become an issue as the cost of cancer care continues to rise significantly. Cost sharing policies have increased out-of-pocket expenses for patients, leading to poorer financial well-being, quality of life, psychosocial health, and treatment adherence. In this review, we briefly examine some factors affecting the pricing of these new targeted therapies; the effects of financial toxicity on patients; and highlight potential health policy and patient-provider level interventions to address these issues.
\end{abstract}

Keywords: Cost; immuno-oncology; insurance; drug pricing; financial burden

Submitted Dec 23, 2017. Accepted for publication Mar 06, 2018.

doi: 10.21037/atm.2018.03.28

View this article at: http://dx.doi.org/10.21037/atm.2018.03.28

\section{Introduction}

Over the last few decades, cancer treatment has undergone extensive evolution through advances in genomics and a greater understanding of the molecular and immunologic processes that drive cancer. Therapies that target certain cellular biochemical or signaling pathways have risen to the forefront as focus has shifted towards finding agents that could potentially be more effective with higher specificity and fewer toxicities than cytotoxic chemotherapy drugs already in use.

With the advent of drugs like imatinib (1) and trastuzumab (2), the paradigm of cancer drug development shifted towards drugs that could inhibit particular pathways necessary for cancer growth and development. Since these two drugs were first approved, a myriad of other targeted therapies has emerged. Included among these new targeted therapies are agents that seek to activate the immune system to more effectively attack cancer cells. Agents such as ipilimumab (3) and nivolumab (4) are some examples of molecules that block inhibitory lymphocyte receptors and potentiate lymphocyte antitumor activity. Another approach has been to provide active cellular immunotherapy, such as that seen with the use of sipuleucel-T immunotherapy for castration-resistant prostate cancer (5) or with genetically modified T-cells engineered for the treatment of B-cell lymphoma (6). The list of potential avenues with which to approach cancer treatment continues to expand as investigators discover more biochemical markers and mechanisms unique to malignant cells that allow for more directed treatment with less collateral damage to the patient's healthy cells.

However, the balance between continued innovation and monetary cost-both to patients and society-must be weighed as these two issues do not exist in isolation from one another. In 2013, an estimated $\$ 115.4$ billion was spent on personal health care related to cancer (7). By 2020 , the total annual cost of cancer care could range from $\$ 173$ billion to $\$ 207$ billion (8). While the cost of cancer care stems from multiple sources, one concern is that rising expenditures are partly fueled by the increasingly expensive therapeutics entering the market. Many of these new 
targeted therapies cost more than $\$ 100,000$ annually (9). These drug prices are driven by factors such as the cost of research and development, manufacturing costs, and market pressures (10).

These costs have been increasingly shifted to patients through higher deductibles, co-insurance, copayments, and out-of-pocket expenses (11). This financial burden can negatively affect patient outcomes and quality of life, with the term "financial toxicity" increasingly used in medical literature to describe these effects (12). There are implications for patients' financial well-being, their psychosocial health, and ultimately their ability to deal with all of the challenges associated with a cancer diagnosis.

There is a dire need to address these ballooning expenses as they will eventually exceed the ability of both the individual patient and society to sustain them. In 2009, the American Society of Clinical Oncology (ASCO) released a guidance statement calling for greater recognition of the impact of the cost of cancer care as well as underscoring the need for intervention (13). The focus of this review will be to examine the pricing of these new anti-cancer agents, how the burgeoning cost of cancer care has affected patients, and to highlight potential interventions that can alleviate this issue.

\section{Rising cost of targeted therapies}

The pricing of pharmaceuticals has recently garnered greater attention as more focus is being placed on the economic burden of cancer. An example of this was the publicity given to the $\$ 11,000$ per month pricing of zif-aflibercept following an editorial published in the New York Times by physicians from Memorial Sloan-Kettering Cancer Center. In this editorial, they discussed their decision to not add this medication to their formulary as it provided no proven benefit over another that was already being used, despite being double the price (14). This is only one illustration of the attention surrounding the price tag of drugs entering the market in recent years. Prior to 2000 , the average annual cost of cancer drugs was roughly $\$ 5,000-\$ 10,000$. This has inflated dramatically within the past decade, with some medications costing over $\$ 10,000$ per month (15). In 2015, the median price of the 13 cancer drugs approved by the U.S. Food and Drug Administration (FDA) was $\$ 145,000$ annually (16). The difference in pricing between the "traditional" cytotoxic chemotherapy agents and the newer biologic and targeted agents has a dramatic impact on the cost of different treatment regimens. For example, the addition of bevacizumab or panitumumab to the regimen of modified fluorouracil, leucovorin, and oxaliplatin (mFOLFOX-6) for metastatic colon cancer resulted in a $213 \%$ and $357 \%$ increase in cost respectively for 6 months of therapy (17). We hope to examine some of the underlying causes of this drastic price increase by reviewing how prices for these drugs are set by developers as well as how they change over time.

\section{Factors affecting cost}

\section{Research and development}

There are numerous factors that contribute to the pricing of these drugs. The cost of research \& development (R\&D) is often cited as a major issue, as companies must invest significant resources in the development, manufacturing, and testing of their product. Pharmaceutical companies accept a certain amount of risk in investing capital into a venture in which many products fail before ever making it into the market, and this risk is factored into their pricing. A recent estimate by DiMasi et al. placed the cost of new drug development at $\$ 2.6$ billion, which is a greater than three-fold increase from the $\$ 802$ million estimated in 2003 (18). However, a criticism of this estimate is that it fails to take into account the various subsidies provided via the federal government through $\mathrm{R} \& \mathrm{D}$ tax credits (19). The study also fails to take into account the contribution of external research in discovering many of the underlying mechanisms that these drugs target (19). There is a pervasive narrative that innovative treatments originate from private pharmaceutical companies and this is often used to justify the high prices of their products. However, a review conducted by Kesselheim et al. of the development process of 26 transformative drugs or drug classes (imatinib and rituximab are included among these), approved by the FDA between 1984 and 2009, found that oftentimes the initial research necessary to develop these drugs was done at major academic medical centers with public funding (20). In particular, the authors highlight the contributions of academia in elucidating the underlying mechanism of various disease processes which led to the later development of drugs such as alglucerase, epoetin alfa, imatinib, tamsulosin, and fluoxetine. This is not to say that the pharmaceutical industry has not pioneered innovative treatments, but rather that the process is much more nuanced and that $\mathrm{R} \& \mathrm{D}$ costs may be overestimated. Indeed, other studies have estimated much lower R\&D costs based on different models. Prasad and Mailankody 
utilized U.S. Securities and Exchange Commission filings for 10 companies and the cancer drugs that they developed between 2006-2015, and estimated that the average cost to developing a cancer drug was $\$ 648$ million (21). The difference between these two estimates clearly shows that more transparency from the pharmaceutical industry and further investigation are necessary to determine the actual $\mathrm{R} \& \mathrm{D}$ costs of new drugs.

\section{Market factors}

Within a free-market economy, the pricing of a product is theoretically dictated by simple supply and demand. However, in the market of anti-cancer medications, the forces at play are much more complex. Patients with cancer are often more willing to undergo high cost treatments with disregard to the financial consequences, even if the treatment offers only marginal benefits. Thus, pharmaceutical companies have little incentive to price their products lower if patients are willing to pay higher prices.

It is theorized that pharmaceutical companies actually price their new therapies based on the "Market Spiral Pricing Strategy" (22). This involves setting the price of the new therapy $10-20 \%$ higher than similar drugs currently on the market (15). It is a "reference price" model of demand in which consumer decisions are based around a reference price instead of based on the intrinsic value of a product. Pharmaceutical companies are able to price their new products within a certain range (referred to as the "zone of indifference") such that consumers ignore the slight increase in reference price. As long as there is no drastic difference in benefit or risk between the new drug and the ones currently on the market, consumers become habituated to the higher prices over time (23), allowing the companies to increase the price again with the next drug that is introduced to the market.

\section{Drug pricing changes after entering the market}

In theory, the prices of medications should decrease as the forces of a free-market economy establish a fair price, i.e., when competitors enter the market, generic forms are released upon patent expiration, and as indications for each drug are broadened, leading to an increased number of consumers. However, recent evidence shows that this may not be the case. On the contrary, the prices of older therapies continue to increase annually, parallel to the everincreasing launch prices of new therapies. An analysis of the change in pricing of 32 orally administered anti-cancer therapies introduced to the market between 2000-2014 showed that most of the therapies had substantial price increases throughout the 14-year period-imatinib had one of the largest increases in monthly spending, going from $\$ 3,346$ to $\$ 8,479$ (24). Another study found that the price of 13 injectable targeted therapies covered under Medicare Plan B had a mean annual price increase of 2-5\% from their launch date to 2017 (25). The investigators found no dependent relationship between the addition of FDA supplemental approvals, entrance of competitors into the marketplace, or addition of off-label indications with the price changes. Moreover, as an example of the failure of competing therapies to lead to lower prices, the price of cetuximab continued to increase despite the 2006 introduction of panitumumab (a competitor also indicated for use in metastatic colorectal cancer) (25).

\section{Financial toxicity of cancer treatment}

The monetary burden of cancer treatment has risen dramatically over the last few decades. In order to mitigate these increasing expenditures, public and private payers have implemented cost sharing measures that shift more of the financial burden to patients. This has resulted in higher patient out-of-pocket payments. Patients with cancer spend a median of $\$ 1,730-\$ 4,727$ annually on outof-pocket treatment-related expenses, which is an estimated \$976-\$1,170 higher than patients without cancer (26). Studies have shown that the increased out-of-pocket expenses have affected adult patients of all ages, regardless of insurance status. Bernard et al. analyzed data from the Medical Expenditure Panel Survey from 2001-2008 and found that $13.4 \%$ of patients with cancer, ages $18-64$, had out-of-pocket costs exceeding $20 \%$ of their income (27). Their study also revealed that the patients who experienced higher out-of-pocket costs were more likely to be age 55-64 years, non-Hispanic black, single, unemployed, have lower income, lower education level, other chronic conditions, and were likely to be living in nonmetropolitan areas. Within the Medicare population, one study found that patients were incurring out-of-pocket expenses that were an average of $23.7 \%$ of their household income- $10 \%$ of the patients had expenses exceeding $60 \%$ of their household income (28). Overall, these rising out-of-pocket expenses are concerning as high financial burden has been associated with delays and poorer access to medical care, as detailed below (29).

The implementation of the Patient Protection and 
Affordable Care Act (ACA) attempted to alleviate some of this financial burden through Medicaid expansion, premium tax credits, and setting a cap on out of pocket payments. Prior to ACA enactment, Blumberg et al. determined that $44.8 \%$ of health insurance units (a family unit including spouses and dependent children 18 years of age or younger and full-time student dependents up to age 23) had healthcare expenses that exceeded $10 \%$ of the unit's before-tax income (30). This was based on the Medical Expenditure Panel Survey Household Component data between 2001-2009. The expectation was that the new healthcare legislation would decrease the number of uninsured patients by offering more affordable insurance plans. A simulated model by Davidoff et al. estimated that $30 \%$ of pre-ACA uninsured cancer patients would be eligible for Medicaid while another 31\% would be able to receive tax credits through the ACA. Of the patients who reported financial hardship, $14 \%$ of them would be eligible for tax credits while 39\% would be eligible for Medicaid coverage (31). However, the ACA left the decision to expand Medicaid coverage to the discretion of individual states-a large portion opted to not implement Medicaid expansions which ultimately reduced the impact of the ACA's expanded coverage. Also, insured patients can still incur significant financial toxicity due to burdensome out-of-pocket expenses. In this case they are considered "underinsured" (12).

Patients are bearing the brunt of rising healthcare expenditures. Although patients have benefitted from these new targeted therapies from a medical standpoint, they are experiencing greater financial toxicity. As a result, they are experiencing more financial distress, reduced quality of life, and poorer outcomes. Here, we will review some of the downstream effects of financial toxicity.

\section{Financial well-being}

Patients with cancer are at greater risk for experiencing financial hardship due to the steep price of cancer care. In one study of 1,202 adult cancer survivors, $20.4 \%$ of the cohort reported experiencing financial difficulties which was defined as being unable to pay for their cancer-related medical bills; having to borrow money; going into debt; filing for bankruptcy; or other financial sacrifices (32). Patients who were female, between 18-64 years of age, nonwhite, and who were forced to make a change in their employment (taking extended leave or switching to parttime) were more likely to report financial difficulties. In a prospective, cohort study of 1,000 patients with colorectal or lung cancer, $48 \%$ reported some degree of financial burden (33). Forty-seven percent of those among another cohort of 174 patients with solid tumor malignancies reported "significant or catastrophic" financial burden (34). The financial burden that patients incur through their treatment costs can be compounded by decreased income, a result of lost work productivity (35). There is evidence to suggest that younger, working-age patients are more at risk than those $>65$ years of age (36).

For some patients, the financial burden can be so great that they are forced into insolvency. Ramsey et al. studied patients with cancer in the state of Washington and found them to be 2.65 times more likely to declare bankruptcy than people without cancer, with younger patients $2-5$ times as likely compared to patients 65 years and older (37). A subsequent study by the same researchers found that cancer patients who filed for bankruptcy faced a $64 \%$ higher risk of mortality (38). Bankruptcy filings due to medical costs are becoming more prevalent (39) so finding ways to mitigate severe financial distress are critical.

\section{Psychosocial distress and quality of life}

Financial distress from cancer has been linked to higher risk of psychosocial distress and worse quality of life. The interplay between financial burden and emotional distress has been well-documented in the literature. Meeker $e t$ al. found an association between financial distress and overall distress levels in a cohort of 120 insured, affluent, and welleducated patients. Twenty-nine percent of the patients had "high or overwhelming" financial distress, $65 \%$ of the patients had levels of overall distress that were considered clinically significant, and $66 \%$ reported a component of emotional distress. Their results suggested that emotional distress, when compounded with financial burden, augmented overall distress levels (40). Other studies have reiterated the association between financial burden and worse psychological outcomes. Sharp et al. found a threefold increased risk of depression in patients experiencing financial stress (41). Kale and Carroll found that patients who reported three or more financial problems had 2.56 times greater odds of experiencing psychological distress (42). In a study of 3,724 cancer patients, 52\% reported high psychological distress (43), indicating that cancer patients are already inherently more at risk for experiencing psychosocial distress without the added burden of financial stressors.

Studies have also shown a link between financial burden and poorer quality of life. Patients are often forced to make 
many adjustments in response to their cancer, and financial stress can have a harmful impact on their overall well-being. When asked to subjectively report perceived financial burdens and to rate quality of life in the 2010 National Health Interview Survey, patients with "a lot" of financial problems were 4 times less likely to report "good" or better quality of life than those without financial problems (44). Other studies support this link between financial toxicity and poorer quality of life across different cancer types such as colorectal and lung cancer $(33,45)$, multiple endocrine neoplasia type I-related cancers (46), and advanced cancers (breast, colorectal, lung, or prostate) (47).

\section{Treatment adberence}

Our prior work has shown that patients may deal with their financial burden by delaying or foregoing their care-they may take less medication than prescribed, utilize overthe-counter drugs in place of prescribed medications, decline procedures, and skip appointments in an attempt to defray costs (12). The combination of increasing drug prices, particularly of oral targeted anticancer drugs, and increased cost sharing has made patients more vulnerable to medication nonadherence. Access and adherence to oral therapies in particular are critical given that they are playing a larger role in the treatment of cancer. In a population of Medicare Part D patients who were taking at least 1 of the 5 top selling oral cancer drugs covered under Part D in 2008 , up to $70 \%$ reported discontinuation of their cancer therapy due to expensive out-of-pocket costs (48). Streeter et al. found that Medicare patients had a higher burden of cost sharing than those with private insurance, and that an out-of-pocket cost of greater than $\$ 500$ was associated with a $25 \%$ rate of abandonment of oral therapy versus $6 \%$ for costs of less than $\$ 100$ (49). Huntington et al. studied a cohort of 100 patients with multiple myeloma, a population that has a high rate of use of novel targeted therapies, and found that $17 \%$ reported delays in treatment and $10 \%$ discontinued treatment due to high costs (50).

The literature also indicates that there are disparities in terms of who is at greater risk of non-compliance. Patients who are younger, have lower income, and are uninsured appear to be at greater risk of medication nonadherence based on a growing body of evidence (51-55). A study conducted by Wong et al. reinforces the relationship between income and treatment nonadherence. They found that patients with lower socioeconomic status are more likely to decline treatment regardless of efficacy or toxicity in order to avoid paying out-of-pocket expenses (56). Healthcare reform in recent years has attempted to reduce disparity based on income and access to care. There is emerging data that expansions in health insurance coverage through the ACA has led to a decrease in the percentage of adults (age 18-64 years) with cancer who had limited access to prescription drugs due to cost. Based on data from the 2010-2015 National Health Interview Survey, the percentage of adult cancer patients lacking adequate access to drugs due to cost has dropped from $13.8 \%$ to $8.6 \%$ (57).

\section{Interventions to address financial toxicity}

The need for intervention is clear as U.S. expenditures on healthcare continue to skyrocket. Although cancer care only accounts for a portion of these expenditures, and the amount spent on expensive targeted therapies an even smaller fraction, it remains a critical issue that needs to be addressed. At the societal level, this is clearly an unsustainable pace with longstanding ramifications for the future of not just oncology, but of healthcare as a whole. The challenge is to find practical solutions that control costs to both payers and patients, while still promoting innovation from pharmaceutical companies. We acknowledge that there are many competing interests on the part of patients, providers, industry, and policymakers that must be addressed in order to find an equitable solution. We will review potential solutions both in regard to health policy interventions, as well as those that can be implemented at the patient-provider level that could address the aforementioned issues while still benefiting all stakeholders.

\section{Interventions to reduce drug costs}

There have been many suggestions for different mechanisms to curb rising costs. From a political standpoint, various legislative proposals have included the restructuring of current Medicare regulations, laws mandating increased transparency from pharmaceutical companies regarding drug pricing, and the implementation of different reimbursement models.

\section{Legislation}

One proposal has been to enact legislation allowing for Medicare to negotiate the pricing of drugs, which could save an estimated $\$ 40$ to $\$ 80$ billion per year (58). Furthermore, altering current legislation which mandates Medicare to 
cover all anticancer agents approved by the FDA would allow for greater control of utilization, and ultimately cost, through Medicare's ability to choose which drugs it would cover (59). There is also concern that Medicare Part B's reimbursement structure of average selling price plus $6 \%$ incentivizes physicians to prescribe more expensive agents. At the state level, there has also been pressure to enact legislation targeted toward the pharmaceutical industry. As of June 2016, ten states were considering bills related to increasing transparency of research and development costs for pharmaceuticals (60). However, it is unclear whether this legislation will have any meaningful effect as there are currently no mechanisms from the payer perspective for determining how to use $\mathrm{R} \& \mathrm{D}$ costs to determine reimbursement.

\section{Alternative reimbursement model}

A "pay-for-performance" approach to reimbursement is a notion that has been gaining significant traction. In this model, payers would reimburse based on the effectiveness of a medication, allowing for selection of the most costeffective drugs. An example of this outcomes-based pricing is the recent agreement between the Centers for Medicare and Medicaid Services (CMS) and Novartis regarding their new CAR-T cell therapy called Kymriah. The reimbursement for Kymriah is based on its achieved clinical outcomes, in which payment only occurs if patients respond to the drug by the end of the first month (61). The National Institute for Health and Clinical Excellence (NICE) in the United Kingdom has a similar agreement with the makers of Velcade (bortezomib), in which patients who achieved a minimum response within the first 4 cycles of treatment (defined as a $25 \%$ or greater reduction in serum M-protein levels) would have their treatments funded by the National Health Service. Patients who had stable or progressive disease (less than 25\% improvement in serum M-protein) would have their treatment costs reimbursed by the manufacturers (62). This type of value-based contract has the potential to improve patient outcomes while still rewarding pharmaceutical companies for their innovation. Although it is a popular concept, there is still limited implementation of this type of payment model. In a survey of 101 pharmaceutical executives, $71 \%$ believed that this was a beneficial model for patients, payers, and industry. However, only $25 \%$ of the respondents have participated in this type of contract (63). With the partnership between Novartis and CMS serving as an archetype, the hope is that more companies will adopt outcomes-based pricing.

\section{Assessing the value of targeted therapies}

A review by Barnes et al. of solid tumor treatments approved between 2000 and 2015 revealed a disconnect between the launch pricing of drugs and their efficacy, suggesting that the rising cost of targeted therapies has not led to a proportional increase in clinical benefit for patients (64). Of late, many of the new agents that are approved only demonstrate marginal benefit over the current therapies used for the same indication. In response to this issue, ASCO convened four disease-specific working groups in 2014 and established recommended targets for meaningful clinical trial goals (65). Fojo et al. looked at therapies approved for solid tumors between 2002 and 2014 and found that only $42 \%$ of the 71 therapies met the goals set by the ASCO committee (66). A subsequent study of the 47 therapies approved by the FDA between 2014-2016 showed that only $19 \%$ met the suggested overall survival goals (67). Clearly, many of the agents that are brought to the market are failing to provide increased value.

It is often difficult to compare these drugs head-tohead with those that are already on the market, as there has historically been a dearth of cost-effectiveness data comparing targeted therapies. This information would be highly useful for providers and patients to make informed decisions. A standardized method of comparing cost among different drugs is to use the cost per quality-adjusted life year (QALY) gained (68). In recent years, as concern with the growing financial burden of cancer care has increased, there has been a subsequent increase in the number of studies that examine the cost-effectiveness of various targeted therapies.

Cressman et al. analyzed 50 drugs approved between 1994-2013 as first- or second-line treatment for metastatic or advanced breast, colorectal, or non-small cell lung cancer (NSCLC). Of these 50, only 17 demonstrated significantly superior overall survival than their comparison drugs. The targeted therapies for metastatic colorectal cancer were found to have cost-effectiveness ratios exceeding $\$ 100,000$ per life year gained (69). A systematic review by Geynisman et al. of therapeutic cancer vaccines and immune therapy agents was conducted in 2014 to determine which drugs had cost-effectiveness analyses performed since entering the market. The authors found that of 16 agents, only 5 had costeffectiveness analyses (rituximab, trastuzumab, bevacizumab, cetuximab, and panitumumab) and of these, only rituximab was considered to be cost-effective (70). Within the last 2 to 3 years, more studies have examined the cost-effectiveness of various targeted therapies such as nivolumab and 
pembrolizumab in the treatment of advanced NSCLC (71) and $B R A F$ wild-type advanced melanoma (72); bevacizumab as a first- and second-line agent in combination with chemotherapy for metastatic colorectal cancer (73); regorafenib (74) and ramucirumab (75) for metastatic colorectal cancer; and pertuzumab for metastatic HER2positive breast cancer (76).

Although efforts are being made to address the escalating price of targeted therapies, there remains a significant amount of work to be done to maximize the value of cancer care for patients in this country. In a comparison of health gains obtained per dollar spent between the United States and eight other developed nations, the U.S. lagged behind despite spending the most on cancer agents. In particular, Japan had nearly 7 times the amount of health gains per dollar spent on cancer drugs compared to the U.S. (77).

\section{Value-based insurance design (VBID)}

One effort to encourage the use of high-value therapies has been the adoption of VBID. This model adjusts the out-ofpocket costs to a patient based on the clinical value of the therapy-high value services that have the greatest positive impact would have lower cost-sharing while lower value services would have a greater cost-sharing burden (78). This design was meant to encourage patients to pursue therapies that had high-level evidence of clinical effectiveness and to reduce the overall barriers to high value medical services through supplemental benefits or reduced costsharing options. Evidence shows that reduction of out-ofpocket costs through VBID programs improves medication adherence by $2.7 \%$ to $3.4 \%$ (79). By restructuring insurance plans to incentivize the use of high-quality therapies, VBID could potentially reduce the monetary burden on patients while improving their outcomes.

\section{Patient and provider level interventions}

A portion of the responsibility also lies with providers to deliver high-quality care for patients and to practice good stewardship of resources. In order to do so, physicians must have the appropriate information in order to decide which therapies hold the best value for patients. In 2015, ASCO released a value framework to give providers a physicianguided tool to compare new treatments with the current standard of care for both advanced cancer and curative treatment (80). The framework assigns points based on clinical benefit, toxicity, and cost and allows providers to engage in shared decision making with patients. ASCO has identified cost discussions as a critical component of high-quality care for patients (13). Cost concerns are prevalent among cancer patients, but evidence suggests that they are not frequently addressed. Stump et al. surveyed 400 cancer patients, $30 \%$ of whom reported concerns with affording their treatments (81). In a survey of 132 patients by Meisenberg et al., 47\% reported high financial stress, but $71 \%$ reported that they rarely had discussions of cost with their providers (82).

Data have shown that engaging patients in cost discussions can reduce out-of-pocket expenses. In a study of 300 patients, $19 \%$ reported that they had spoken to their physician regarding cost. Among that cohort, 57\% endorsed reduced financial burden as a result of the discussion (83). There is also evidence to suggest that discussing out-of-pocket costs may be related to medication non-adherence (84). It is theorized that the patients most likely to engage in cost discussions are those who are at greatest risk of experiencing significant financial burden, and subsequently at increased risk for treatment noncompliance. Screening for patients at risk for financial toxicity needs to be implemented as part of common clinical practice given the many consequences of burdensome out-of-pocket costs. However, more research is required to determine the appropriate time at which screening should be performed, the most appropriate clinical screening tool(s) to use, and how other solutions can be implemented in order to address rising cancer treatment costs from multiple angles (85). One potential tool is the COmprehensive Score for financial Toxicity (COST) measure, an 11-item patient-reported outcome measure that has been validated as a tool to assess for financial toxicity in cancer patients (86). Clinically relevant measures such as this will be useful for providers to identify which patients are most at risk.

Physicians may also benefit from additional education or training regarding how to best conduct these cost discussions with patients and as to what resources are available. While a majority of oncologists agree that having these discussions is a critical component of shared decision making, a large proportion express discomfort in having them (87). A portion of oncologists also believe that clinical encounters are not appropriate venues for discussions of cost, with concerns that societal cost should not play a role in clinical decision making (87). An important distinction to make here is that affordability conversations with patients only help patients better afford the best possible care. ASCO's guidelines have made it clear that in order to address the rising cost of cancer care, physicians must 
take on a greater responsibility in engaging patients in such discussions.

\section{Conclusions}

The development of molecular and immune therapies for the treatment of cancer has greatly improved outcomes and survival for patients. However, drastically increasing drug prices and marginal improvements in efficacy of newly approved agents has led to a significant increase in patient financial burden with minimal improvements in their clinical benefit. As a result, patients are experiencing increasing financial toxicity from these therapies which has a direct impact on their quality of life, treatment adherence, and outcomes. This review has highlighted some of the issues surrounding the skyrocketing price of targeted therapies such as the rationale behind pricing, trends in launch pricing and in pricing after drugs enter the market, how financial toxicity impacts patients, and potential solutions. It is clear that a new approach must be taken in the way new drugs are assessed for value, and that the current model for reimbursement must be altered so that new targeted therapies are chosen based on costeffectiveness instead of those that provide maximal profit. Furthermore, cost discussions need to be implemented as part of routine clinical care and clinically useful screening tools need to be developed to screen for patients most at risk. The responsibility lies with all parties-industry members, payers, providers, and patients-to collaborate and find solutions that are to the benefit of all.

\section{Acknowledgements}

None.

\section{Footnote}

Conflicts of Interest: Dr. SY Zafar reports the following potential conflicts of interest: employment, Novartis (spouse); stocks, Novartis (spouse); consulting, AIM Speciality Health. DR. G Tran has no conflicts of interest to declare.

\section{References}

1. Druker BJ, Talpaz M, Resta DJ, et al. Efficacy and safety of a specific inhibitor of the BCR-ABL tyrosine kinase in chronic myeloid leukemia. N Engl J Med 2001;344:1031-7.
2. Slamon DJ, Leyland-Jones B, Shak S, et al. Use of chemotherapy plus a monoclonal antibody against HER2 for metastatic breast cancer that overexpresses HER2. N Engl J Med 2001;344:783-92.

3. Hodi FS, O'Day SJ, McDermott DF, et al. Improved survival with ipilimumab in patients with metastatic melanoma. N Engl J Med 2010;363:711-23.

4. Robert C, Long GV, Brady B, et al. Nivolumab in previously untreated melanoma without BRAF mutation. N Engl J Med 2015;372:320-30.

5. Kantoff PW, Higano CS, Shore ND, et al. Sipuleucel-T immunotherapy for castration-resistant prostate cancer. $\mathrm{N}$ Engl J Med 2010;363:411-22.

6. Kochenderfer JN, Wilson WH, Janik JE, et al. Eradication of B-lineage cells and regression of lymphoma in a patient treated with autologous $\mathrm{T}$ cells genetically engineered to recognize CD19. Blood 2010;116:4099-102.

7. Dieleman JL, Baral R, Birger M, et al. US Spending on Personal Health Care and Public Health, 1996-2013. JAMA 2016;316:2627-46.

8. Mariotto AB, Yabroff KR, Shao Y, et al. Projections of the cost of cancer care in the United States: 2010-2020. J Natl Cancer Inst 2011;103:117-28.

9. Mailankody S, Prasad V. Five Years of Cancer Drug Approvals: Innovation, Efficacy, and Costs. JAMA Oncol 2015;1:539-40.

10. Glode AE, May MB. Rising Cost of Cancer Pharmaceuticals: Cost Issues and Interventions to Control Costs. Pharmacotherapy 2017;37:85-93.

11. Goldman DP, Joyce GF, Zheng Y. Prescription drug cost sharing: associations with medication and medical utilization and spending and health. JAMA 2007;298:61-9.

12. Zafar SY, Peppercorn JM, Schrag D, et al. The financial toxicity of cancer treatment: a pilot study assessing outof-pocket expenses and the insured cancer patient's experience. Oncologist 2013;18:381-90.

13. Meropol NJ, Schrag D, Smith TJ, et al. American Society of Clinical Oncology guidance statement: the cost of cancer care. J Clin Oncol 2009;27:3868-74.

14. Bach PB, Saltz LB, Wittes RE. In Cancer Care, Cost Matters. The New York Times. 2012. Available online: http://www.nytimes.com/2012/10/15/opinion/a-hospitalsays-no-to-an-11000-a-month-cancer-drug.html

15. Experts in Chronic Myeloid L. The price of drugs for chronic myeloid leukemia (CML) is a reflection of the unsustainable prices of cancer drugs: from the perspective of a large group of CML experts. Blood 2013;121:4439-42.

16. Kantarjian H, Patel Y. High cancer drug prices 4 years 
later-Progress and prospects. Cancer 2017;123:1292-7.

17. Nadeem H, Jayakrishnan TT, Rajeev R, et al. Cost Differential of Chemotherapy for Solid Tumors. J Oncol Pract 2016;12:e299-307,251.

18. DiMasi JA, Grabowski HG, Hansen RW. Innovation in the pharmaceutical industry: New estimates of R\&D costs. J Health Econ 2016;47:20-33.

19. Avorn J. The $\$ 2.6$ billion pill - methodologic and policy considerations. N Engl J Med 2015;372:1877-9.

20. Kesselheim AS, Tan YT, Avorn J. The roles of academia, rare diseases, and repurposing in the development of the most transformative drugs. Health Aff (Millwood) 2015;34:286-93.

21. Prasad V, Mailankody S. Research and Development Spending to Bring a Single Cancer Drug to Market and Revenues After Approval. JAMA Intern Med 2017;177:1569-75.

22. Light DW, Kantarjian H. Market spiral pricing of cancer drugs. Cancer 2013;119:3900-2.

23. Howard DH, Bach PB, Berndt ER, et al. Pricing in the Market for Anticancer Drugs. J Econ Perspect 2015;29:139-62.

24. Dusetzina SB. Drug Pricing Trends for Orally Administered Anticancer Medications Reimbursed by Commercial Health Plans, 2000-2014. JAMA Oncol 2016;2:960-1.

25. Gordon N, Stemmer SM, Greenberg D, et al. Trajectories of injectable cancer drug costs after launch in the United States. J Clin Oncol 2018;36:319-25.

26. Bestvina CM, Zullig LL, Zafar SY. The implications of out-of-pocket cost of cancer treatment in the USA: a critical appraisal of the literature. Future Oncol 2014;10:2189-99.

27. Bernard DS, Farr SL, Fang Z. National estimates of out-of-pocket health care expenditure burdens among nonelderly adults with cancer: 2001 to 2008. J Clin Oncol 2011;29:2821-6.

28. Narang AK, Nicholas LH. Out-of-Pocket Spending and Financial Burden Among Medicare Beneficiaries With Cancer. JAMA Oncol 2017;3:757-65.

29. Guy GP Jr, Yabroff KR, Ekwueme DU, et al. Healthcare Expenditure Burden Among Non-elderly Cancer Survivors, 2008-2012. Am J Prev Med 2015;49:S489-97.

30. Blumberg LJ, Waidmann TA, Blavin F, et al. Trends in health care financial burdens, 2001 to 2009. Milbank Q 2014;92:88-113.

31. Davidoff AJ, Hill SC, Bernard D, et al. The Affordable Care Act and Expanded Insurance Eligibility Among
Nonelderly Adult Cancer Survivors. J Natl Cancer Inst $2015 ; 107$.

32. Yabroff KR, Dowling EC, Guy GP Jr, et al. Financial Hardship Associated With Cancer in the United States: Findings From a Population-Based Sample of Adult Cancer Survivors. J Clin Oncol 2016;34:259-67.

33. Zafar SY, McNeil RB, Thomas CM, et al. Populationbased assessment of cancer survivors' financial burden and quality of life: a prospective cohort study. J Oncol Pract 2015;11:145-50.

34. Chino F, Peppercorn J, Taylor DH Jr, et al. Self-reported financial burden and satisfaction with care among patients with cancer. Oncologist 2014;19:414-20.

35. Bennett JA, Brown P, Cameron L, et al. Changes in employment and household income during the 24 months following a cancer diagnosis. Support Care Cancer 2009; 17:1057-64.

36. Meeker CR, Wong YN, Egleston BL, et al. Distress and Financial Distress in Adults With Cancer: An Age-Based Analysis. J Natl Compr Canc Netw 2017;15:1224-33.

37. Ramsey S, Blough D, Kirchhoff A, et al. Washington State cancer patients found to be at greater risk for bankruptcy than people without a cancer diagnosis. Health Aff (Millwood) 2013;32:1143-52.

38. Ramsey SD, Bansal A, Fedorenko CR, et al. Financial Insolvency as a Risk Factor for Early Mortality Among Patients With Cancer. J Clin Oncol 2016;34:980-6.

39. Himmelstein DU, Thorne D, Warren E, et al. Medical bankruptcy in the United States, 2007: results of a national study. Am J Med 2009;122:741-6.

40. Meeker CR, Geynisman DM, Egleston BL, et al. Relationships Among Financial Distress, Emotional Distress, and Overall Distress in Insured Patients With Cancer. J Oncol Pract 2016;12:e755-64.

41. Sharp L, Carsin AE, Timmons A. Associations between cancer-related financial stress and strain and psychological well-being among individuals living with cancer. Psychooncology 2013;22:745-55.

42. Kale HP, Carroll NV. Self-reported financial burden of cancer care and its effect on physical and mental healthrelated quality of life among US cancer survivors. Cancer 2016;122:283-9.

43. Mehnert A, Hartung TJ, Friedrich M, et al. One in two cancer patients is significantly distressed: Prevalence and indicators of distress. Psychooncology 2018;27:75-82.

44. Fenn KM, Evans SB, McCorkle R, et al. Impact of Financial Burden of Cancer on Survivors' Quality of Life. J Oncol Pract 2014;10:332-8. 
45. Lathan CS, Cronin A, Tucker-Seeley R, et al. Association of Financial Strain With Symptom Burden and Quality of Life for Patients With Lung or Colorectal Cancer. J Clin Oncol 2016;34:1732-40.

46. Peipert BJ, Goswami S, Helenowski I, et al. Financial burden is associated with worse health-related quality of life in adults with multiple endocrine neoplasia type 1 . Surgery 2017;162:1278-85.

47. Delgado-Guay M, Ferrer J, Rieber AG, et al. Financial Distress and Its Associations With Physical and Emotional Symptoms and Quality of Life Among Advanced Cancer Patients. Oncologist 2015;20:1092-8.

48. Kaisaeng N, Harpe SE, Carroll NV. Out-of-pocket costs and oral cancer medication discontinuation in the elderly. J Manag Care Spec Pharm 2014;20:669-75.

49. Streeter SB, Schwartzberg L, Husain N, et al. Patient and plan characteristics affecting abandonment of oral oncolytic prescriptions. J Oncol Pract 2011;7:46-51s.

50. Huntington SF, Weiss BM, Vogl DT, et al. Financial toxicity in insured patients with multiple myeloma: a crosssectional pilot study. Lancet Haematol 2015;2:e408-16.

51. Kaul S, Avila JC, Mehta HB, et al. Cost-related medication nonadherence among adolescent and young adult cancer survivors. Cancer 2017;123:2726-34.

52. Nipp RD, Zullig LL, Samsa G, et al. Identifying cancer patients who alter care or lifestyle due to treatment-related financial distress. Psychooncology 2016;25:719-25.

53. Kent EE, Forsythe LP, Yabroff KR, et al. Are survivors who report cancer-related financial problems more likely to forgo or delay medical care? Cancer 2013;119:3710-7.

54. Zheng Z, Han X, Guy GP Jr, et al. Do cancer survivors change their prescription drug use for financial reasons? Findings from a nationally representative sample in the United States. Cancer 2017;123:1453-63.

55. de Souza JA, Kung S, O'Connor J, et al. Determinants of Patient-Centered Financial Stress in Patients With Locally Advanced Head and Neck Cancer. J Oncol Pract 2017;13:e310-8.

56. Wong YN, Egleston BL, Sachdeva K, et al. Cancer patients' trade-offs among efficacy, toxicity, and out-ofpocket cost in the curative and noncurative setting. Med Care 2013;51:838-45.

57. Gonzales F, Zheng Z, Yabroff KR. Trends in Financial Access to Prescription Drugs Among Cancer Survivors. J Natl Cancer Inst 2018;110.

58. Kantarjian H, Steensma D, Rius Sanjuan J, et al. High cancer drug prices in the United States: reasons and proposed solutions. J Oncol Pract 2014;10:e208-11.
59. Bach PB. Limits on Medicare's Ability to Control Rising Spending on Cancer Drugs. N Engl J Med 2009;360:626-33.

60. Sarpatwari A, Avorn J, Kesselheim AS. State initiatives to control medication costs -- can transparency legislation help? N Engl J Med 2016;374:2301-4.

61. Novartis. Novartis receives first ever FDA approval for a CAR-T cell therapy, KymriahTM (tisagenlecleucel, CTL019), for children and young adults with B-cell ALL that is refractory or has relapsed at least twice, 2017. Available online: https://www.novartis.com/news/mediareleases/novartis-receives-first-ever-fda-approval-car-tcell-therapy-kymriahtm-ctl019

62. NICE. Summary of Velcade Response Scheme. 2007. Available online: https://www.nice.org.uk/guidance/ta129/ documents/department-of-health-summary-of-responderscheme2

63. PricewaterhouseCoopers $(\mathrm{PwC})$. Launching into value: Pharma's quest to align drug prices with outcomes, 2017. Available online: https://www.pwc.com/us/en/healthindustries/health-research-institute/publications/assets/ value-based-drug-pricing.pdf

64. Barnes TA, Amir E, Templeton AJ, et al. Efficacy, safety, tolerability and price of newly approved drugs in solid tumors. Cancer Treat Rev 2017;56:1-7.

65. Ellis LM, Bernstein DS, Voest EE, et al. American Society of Clinical Oncology perspective: Raising the bar for clinical trials by defining clinically meaningful outcomes. J Clin Oncol 2014;32:1277-80.

66. Fojo T, Mailankody S, Lo A. Unintended consequences of expensive cancer therapeutics-the pursuit of marginal indications and a me-too mentality that stifles innovation and creativity: the John Conley Lecture. JAMA Otolaryngol Head Neck Surg 2014;140:1225-36.

67. Kumar H, Fojo T, Mailankody S. An Appraisal of Clinically Meaningful Outcomes Guidelines for Oncology Clinical Trials. JAMA Oncol 2016;2:1238-40.

68. Danzon PM, Taylor E. Drug pricing and value in oncology. Oncologist 2010;15 Suppl 1:24-31.

69. Cressman S, Browman GP, Hoch JS, et al. A Time-Trend Economic Analysis of Cancer Drug Trials. Oncologist 2015;20:729-36.

70. Geynisman DM, Chien CR, Smieliauskas F, et al. Economic evaluation of therapeutic cancer vaccines and immunotherapy: a systematic review. Hum Vaccin Immunother 2014;10:3415-24.

71. Kelly RJ, Smith TJ. Checkpoint Inhibitors in Lung Cancer Are Not Immune from Cost-Effectiveness Analysis. J Thorac Oncol 2016;11:1814-6. 
72. Kohn CG, Zeichner SB, Chen Q, et al. Cost-Effectiveness of Immune Checkpoint Inhibition in BRAF Wild-Type Advanced Melanoma. J Clin Oncol 2017;35:1194-202.

73. Goldstein DA, Chen Q, Ayer T, et al. First- and secondline bevacizumab in addition to chemotherapy for metastatic colorectal cancer: a United States-based costeffectiveness analysis. J Clin Oncol 2015;33:1112-8.

74. Goldstein DA, Ahmad BB, Chen Q, et al. CostEffectiveness Analysis of Regorafenib for Metastatic Colorectal Cancer. J Clin Oncol 2015;33:3727-32.

75. Goldstein DA, El-Rayes BF. Considering Efficacy and Cost, Where Does Ramucirumab Fit in the Management of Metastatic Colorectal Cancer? Oncologist 2015;20:981-2.

76. Durkee BY, Qian Y, Pollom EL, et al. Cost-Effectiveness of Pertuzumab in Human Epidermal Growth Factor Receptor 2-Positive Metastatic Breast Cancer. J Clin Oncol 2016;34:902-9.

77. Salas-Vega S, Mossialos E. Cancer drugs provide positive value in nine countries, but the United States lags in health gains per dollar spent. Health Aff (Millwood) 2016;35:813-23.

78. Centers for Medicare \& Medicaid Services. Medicare Advantage Value-Based Insurance Design Model, 2017. Available online: https://innovation.cms.gov/initiatives/vbid/

79. Gibson TB, Maclean RJ, Chernew ME, et al. Value-based insurance design: benefits beyond cost and utilization. Am

Cite this article as: Tran G, Zafar SY. Financial toxicity and implications for cancer care in the era of molecular and immune therapies. Ann Transl Med 2018;6(9):166. doi: 10.21037/ atm.2018.03.28
J Manag Care 2015;21:32-5.

80. Schnipper LE, Davidson NE, Wollins DS, et al. American Society of Clinical Oncology Statement: A Conceptual Framework to Assess the Value of Cancer Treatment Options. J Clin Oncol 2015;33:2563-77.

81. Stump TK, Eghan N, Egleston BL, et al. Cost concerns of patients with cancer. J Oncol Pract 2013;9:251-7.

82. Meisenberg BR, Varner A, Ellis E, et al. Patient attitudes regarding the cost of illness in cancer care. Oncologist 2015;20:1199-204.

83. Zafar SY, Chino F, Ubel PA, et al. The utility of cost discussions between patients with cancer and oncologists. Am J Manag Care 2015;21:607-15.

84. Bestvina CM, Zullig LL, Rushing C, et al. Patientoncologist cost communication, financial distress, and medication adherence. J Oncol Pract 2014;10:162-7.

85. Khera N, Holland JC, Griffin JM. Setting the stage for universal financial distress screening in routine cancer care. Cancer 2017;123:4092-6.

86. de Souza JA, Yap BJ, Wroblewski K, et al. Measuring financial toxicity as a clinically relevant patient-reported outcome: the validation of the COmprehensive Score for financial Toxicity (COST). Cancer 2017;123:476-84.

87. Schrag D, Hanger M. Medical oncologists' views on communicating with patients about chemotherapy costs: a pilot survey. J Clin Oncol 2007;25:233-7. 